\title{
Solubility and solid phase studies of isomeric phenolic acids in pure solvents
}

\author{
Sérgio M. Vilas-Boas a,b,c , Paula Brandão d , Mónia A.R. Martinss ${ }^{\text {a,b,d }}$, Liliana P. Silva ${ }^{\text {d }}$, Tatiana B. Schreiner ${ }^{\text {a,b }}$, \\ Luciano Fernandes ${ }^{c}$, Olga Ferreira ${ }^{\mathrm{a}, \mathrm{b}, *}$, Simão P. Pinho ${ }^{\mathrm{a}, \mathrm{b}}$ \\ a Centro de Investigação de Montanha (CIMO), Instituto Politécnico de Bragança, Campus de Santa Apolónia, 5300-253 Bragança, Portugal

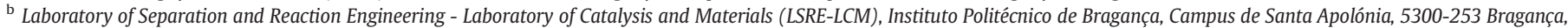 \\ Portugal \\ ' UTFPR-Departamento de Engenharia Química, Universidade Tecnológica Federal do Paraná, 84016-210 Ponta Grossa, Brazil \\ d CICECO - Aveiro Institute of Materials, Department of Chemistry, University of Aveiro, 3810-193 Aveiro, Portugal
}

\section{A R T I C L E I N F O}

\section{Article history:}

Received 30 August 2018

Received in revised form 28 September 2018

Accepted 20 October 2018

Available online 22 October 2018

\section{Keywords:}

Solubility

Phenolic acids

NRTL-SAC

Melting

X-ray diffraction

\begin{abstract}
A B S T R A C T
The solubilities of gallic, protocatechuic, gentisic or $\alpha$-resorcylic acids were measured in nine pure solvents (water, methanol, ethanol, 1-propanol, 2-propanol, 2-butanone, ethyl acetate, acetonitrile and dimethylformamide) at $298.15 \mathrm{~K}$ and $313.15 \mathrm{~K}$, using the analytical isothermal shake-flask method. Additionally, solid phase studies of the selected phenolic acids were carried out using differential scanning calorimetry (DSC) and X-ray diffraction (XRD), giving access to important data on melting properties as well as on the structure of the solid phase before and after the dissolution.

The NRTL-SAC model coupled to the reference solvent approach (RSA) were applied to correlate the solubility data in a set of seven solvents and, after used to predict the solubility in 1-propanol and dimethylformamide. Average relative deviations (ARD) between 28 and $40 \%$ for the correlation and between 16 and $59 \%$ for the predictions were obtained. These values are within the order of magnitude usually found for such type of semipredictive models, using a limited set of data.
\end{abstract}

(c) 2018 Elsevier B.V. All rights reserved.

\section{Introduction}

The phenolic compounds present in natural matrices comprise a very wide range of chemical structures including simple phenols, phenolic acids, coumarins, flavonoids, stilbenes, among others [1]. Many of them are being isolated and extensively studied for their biological and pharmacological activity. In this context, the knowledge of their solubility in water and organic solvents plays an important role in the design of separation processes such as extraction, precipitation or crystallization for application in the food, pharmaceutical, and cosmetic industries.

In the last years, several studies have been focused on the study of the solubility of naturally occurring hydroxybenzoic acids. Since 2007, Noubigh and collaborators have presented some studies on the solubility of gallic, protocatechuic, syringic and vanillic acids in water and organic solvents [2-9]. Additionally, there were also contributions from other researchers that studied salicylic [10-15], gallic [13,16-19],

\footnotetext{
* Corresponding author at: Centro de Investigação de Montanha (CIMO), Instituto Politécnico de Bragança, Campus de Santa Apolónia, 5300-253 Bragança, Portugal.

E-mail address: oferreira@ipb.pt (O. Ferreira).
}

protocatechuic [20,21], syringic [20], veratric [22] and vanillic acids $[23,24]$.

An alternative and reliable path for reducing the amount of experimental work needed to estimate the solubility is the use of predictive and semi-predictive thermodynamic models, especially those based on group contribution approaches. The original UNIFAC model [25] and its modified versions have been applied over the last years to describe the solid-liquid equilibria of phenolic compounds in binary and multicomponent mixtures [23,26-30]. The NRTL model [31] and its variants, especially NRTL-SAC [32], have also shown very satisfactory results in the correlation of the solubilities of phenolic compounds in water and organic systems [19,22,24,28-30,33-36]. Recently, NRTLSAC was also employed to screen the best solvents to optimize the extraction of phenolic compounds in chromatographic processes [37-39].

In this work, the solubility studies are extended to four phenolic acids: gallic acid, protocatechuic acid, gentisic acid and $\alpha$-resorcylic acid. These naturally occurring phenolic acids are all derived from a basic hydroxybenzoic acid structure, varying the number (2 or 3 ) and positions of the hydroxyl groups, as can be seen in Fig. 1.

In order to study solvents of different characteristics, the solubility of the phenolic acids was measured in water and eight organic solvents (methanol, ethanol, 1-propanol, 2-propanol, butanone, ethyl acetate, 
<smiles>O=C(O)c1cc(O)c(O)c(O)c1</smiles>

(a)<smiles>O=C(O)c1ccc(O)c(O)c1</smiles>

(b)

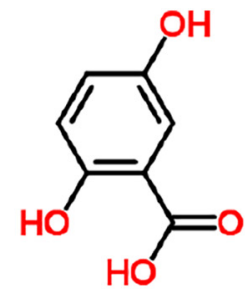

(c)

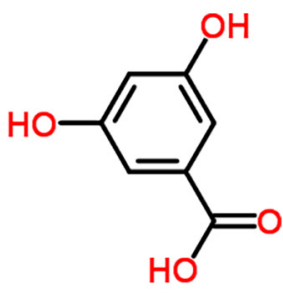

(d)

Fig. 1. Chemical structures of: (a) gallic acid; (b) protocatechuic acid; (c) gentisic acid and (d) $\alpha$-resorcylic acid.

dimethylformamide - DMF, and acetonitrile) at 298.15 and $313.15 \mathrm{~K}$. The obtained data were critically compared to that available in the open literature. Solubility data of several of the studied binary systems has not been reported yet, and regarding gentisic and $\alpha$-resorcylic acids no solubility data were found.

In addition, the temperatures of fusion of the selected phenolic acids were measured by differential scanning calorimetry (DSC) and by a visual method, and the results compared to those previously reported in literature. The melting enthalpies of the acids were also estimated by DSC, while powder and single-crystal X-ray diffraction were employed to investigate the solid phase structures of the pure phenolic acids as commercially supplied, as well as after being recrystallized from the saturated binary solutions.

Finally, the nonrandom two-liquid segment activity coefficient (NRTL-SAC) model was selected to describe the solid-liquid equilibria of the studied binary systems. This semi-predictive model was already satisfactorily applied to describe the solubility of other phenolic compounds [40-42]. Due to the high uncertainty of the melting enthalpy of the phenolic acids, the reference solvent approach (RSA) was combined with the NRTL-SAC model $[30,43]$.

\section{Materials and methods}

\subsection{Chemicals}

All the compounds were used as received, and the solids kept in a desiccator to avoid water contamination. Ultrapure water (resistivity of $18.2 \mathrm{M} \Omega \cdot \mathrm{cm}$, free particles $\geq 0.22 \mu \mathrm{m}$ and total organic carbon $<5$ $\mu \mathrm{g} \cdot \mathrm{dm}^{-3}$ ) was used to perform the solubility experiments. The mass purity and source of all the compounds used in this work are listed in Table 1.

\subsection{Solubility measurements}

The solubility of the phenolic acids was measured by the analytical isothermal shake-flask method as described in detail previously $[13,44]$. Saturated solutions were prepared in a flask by mixing a small amount of solid in excess with around $80 \mathrm{~cm}^{3}$ of solvent. The flasks

Table 1

Minimum mass purity (\%) and supplier of the organic compounds used in this work.

\begin{tabular}{lll}
\hline Component & Mass purity (\%) & Source \\
\hline Gallic acid & $\geq 98$ & Merck KGaA \\
Protocatechuic acid & $\geq 96$ & Merck KGaA \\
Gentisic acid & $\geq 99$ & Merck KGaA \\
$\alpha$-Resorcylic acid & $\geq 98$ & Merck KGaA \\
Methanol & $\geq 99.9$ & Carlo Erba \\
Ethanol & $\geq 99.9$ & Carlo Erba \\
2-Propanol & $\geq 99.8$ & Honeywell \\
1-Propanol & $\geq 99.5$ & Carlo Erba \\
2-Butanone & $\geq 99.5$ & Sigma Aldrich \\
Ethyl acetate & $\geq 99.7$ & Carlo Erba \\
Acetonitrile & $\geq 99.9$ & Sigma Aldrich \\
Dimethylformamide & $\geq 99.9$ & Carlo Erba \\
\hline
\end{tabular}

were covered with aluminum foil, to protect the solutions from light degradation, and they were placed over plate stirrers inside a thermostatic water bath. The temperature control system ensures that the solution temperature is within $\pm 0.1 \mathrm{~K}$ to the set temperature.

First, the flasks containing the prepared solutions were stirred in an ultrasonic bath (Ultrasons-H, JP Selecta S.A.) for $1 \mathrm{~h}$, at the same temperature of the solubility experiment ( 298.15 and $313.15 \mathrm{~K}$ ) to shorten the equilibrium time [45]. From preliminary experiments, it was found that $24 \mathrm{~h}$ and $8 \mathrm{~h}$ are adequate for shaking and settling times, respectively.

After reaching equilibrium, three samples $\left(5 \mathrm{~cm}^{3}\right)$ were collected by using previously heated plastic syringes coupled to a polypropylene filter $(0.45 \mu \mathrm{m}$ pore diameter). The gravimetric method was applied to analyze the samples using an analytical balance $( \pm 0.1 \mathrm{mg})$. The solvent was first evaporated in a ventilation hood and after the samples transferred to a drying oven operating at $343.15 \mathrm{~K}$ for at least 7 days, to complete the drying process.

\subsection{Fusion properties}

The fusion properties of the solid phase of the phenolic acids, as received from suppliers, were measured using two experimental methodologies: the visual method (melting temperature) and differential scanning calorimetry (melting temperature and enthalpy), which are briefly described below.

\subsubsection{Visual method}

Melting temperatures were obtained with an automatic glass capillary device model M-565 from Büchi (50-60 Hz, $150 \mathrm{~W}$, temperature resolution: $0.1 \mathrm{~K})$. A heating rate of $0.1 \mathrm{~K} \cdot \mathrm{min}^{-1}$ was used and the temperature was registered when the last crystal disappeared. For each compound, three independent measurements were carried out.

\subsubsection{Differential scanning calorimetry (DSC)}

Melting properties were determined at atmospheric pressure in a Hitachi DSC7000X device, equipped with a liquid nitrogen cooling system. Samples of $2-5 \mathrm{mg}$, tightly sealed in aluminum pans, were submitted to heating cycles at 1 and $2 \mathrm{~K} \cdot \mathrm{min}^{-1}$. The thermal transitions temperatures were taken as the peak temperature. The equipment was previously calibrated with several standards. The temperature uncertainty calculated through the average of the standard deviation of several consecutive measurements was better than $\pm 2.2 \mathrm{~K}$.

\subsection{Solid-phase studies}

\subsubsection{Samples}

The pure solid compounds as received from the supplier as well as solids crystallized after the gravimetric procedure were analyzed by powder and single crystal X-ray diffraction.

\subsubsection{Powder X-ray diffraction}

Powder XRD data were collected on a X'Pert MPD Philips diffractometer, using Cu-Ka radiation ( $\lambda=1.5406 \AA$ ), with a curved graphite monochromator, a set incident area of $10 \mathrm{~mm}^{2}$, and a flat plate sample 
holder, in a Bragg-Brentano para-focusing optics configuration. Intensity data were collected by the step counting method (step $0.02^{\circ}$ and time $5 \mathrm{~s}$ ) in the range $5^{\circ}<2 \theta<50^{\circ}$.

The cell parameters of suitable crystals of selected phenolic acids in different solvents were determined on a Bruker SMART Apex II diffractometer equipped with a CCD area detector, with monochromated MoK $\alpha$ radiation $(\lambda=0.71073 \AA)$ and operating at $150(2)$ K. After a search in CCDC database [46] we concluded that, in a few cases, protocatechuic acid crystalized in a different crystalline system not yet reported, so Xray data were collected to determine its structure. The crystals of protocatechuic acid after long contact with moist air and sample I5 were put at $40 \mathrm{~mm}$ from the CCD and the spots were measured using 30,80 s counting time. Data reduction was carried out using the SAINT-NT software package. Multi-scan absorption correction was applied to all intensity data using the SADABS program [47].Both structures were solved by a combination of direct methods with subsequent difference Fourier syntheses and refined by full matrix least squares on $\mathrm{F}^{2}$ using the SHELX-2013 suite [48].All non-hydrogen atoms were refined with anisotropic thermal displacements. The $\mathrm{C}-\mathrm{H}$ hydrogen atoms were included on the calculated positions and refined with isotropic parameters equivalent to 1.2 times of those of from the atom they are bonded. The hydrogen atoms bonded to water molecules and also those attached to oxygen in the benzoic acid molecules were obtained from the last Fourier map. Molecular diagrams were drawn by employing the Olex2 software [49]. Crystal data and refinement details are available in Table S1 of Supporting information.

\section{Thermodynamic modelling}

In this work, the NRTL-SAC thermodynamic model was selected to calculate the activity coefficient of the solute in a given solution. A complete description of the equations and fundamentals of the model can be found in previous works from Chen and co-authors [32,50,51]. In summary, NRTL-SAC describes each molecule using four conceptual segments related to the different surface interactions: hydrophobic $(X)$, hydrophilic $(Z)$, polar attractive $\left(Y^{+}\right)$, and polar repulsive $\left(Y^{-}\right)$. The segment descriptors of around 63 solvents were already reported in literature [32]. Thus, a small set of experimental solubility data will be used to estimate the four segment parameters missing for each solute.

Assuming pure solid phase and neglecting the heat capacity change, which is hardly ever known, classical thermodynamics proposes Eq. (1) to describe the solubility curves:

$$
\ln x_{S} \gamma_{S}=\frac{\Delta_{m} H}{R T_{m}}\left(1-\frac{T_{m}}{T}\right)
$$

where $x_{S}$ is the mole fraction of the solute $S, R$ is the ideal gas constant, $T$ is the absolute temperature, $T_{m}$ is the melting temperature of the solute, $\Delta_{m} H$ its melting enthalpy, and $\gamma_{S}$ is the activity coefficient of the solute $S$ [52].

However, melting properties are often missing, and in particular the melting enthalpy value is highly uncertain for the studied compounds, and so the NRTL-SAC model was combined with the reference solvent approach [53,54]. In this methodology, for each solute the term ln $\left(x_{i} \gamma_{i}\right)$ can be considered constant at a given temperature, and the solubility of a solute $S$ in a solvent $i$ can be calculated as a function of the reference solvent $j$ as shown below:

$$
\ln x_{S i}=\ln x_{S j}+\ln \gamma_{S j}\left(T,\left\{x_{S}\right\}_{j}\right)-\ln \gamma_{S i}\left(T,\left\{x_{S}\right\}_{i}\right)
$$

where $x_{S i}$ is the mole fraction solubility of the solute in the solvent $i, x_{S j}$ is the mole fraction solubility of the solute in the reference solvent $j, \gamma_{S i}$ $\left(T,\left\{x_{S}\right\}_{i}\right)$ is the activity coefficient for the solute in solvent $i$, while $\gamma_{S j}$ $\left(T,\left\{x_{S}\right\}_{j}\right)$ is the activity coefficient of the solute in the reference solvent $j$.

For a given data set, the optimal reference solvent $j$ is found by minimizing the sum of the residuals according to Eq. (3):

$$
\min \left|\sum_{i=\text { data }} \delta \ln x_{S, i j}\right|=\left.\min \right|_{i=\text { data }}\left(\ln x_{S i}+\ln \gamma_{S i}\right)-\left(\ln x_{S j}+\ln \gamma_{S j}\right) \mid
$$

being $x_{S, i j}$ the mole fraction of the solute in solvent $i$, assuming that $j$ is the reference solvent, and $N$ is the number of experimental data.

\section{Results and discussion}

\subsection{Experimental solubility}

The solubilities of gallic acid, protocatechuic acid, gentisic acid and $\alpha$-resorcylic acid in water and organic solvents (methanol, ethanol, 1propanol, isopropanol, 2-butanone, ethyl acetate, dimethylformamide and acetonitrile) measured in this work at 298.15 and $313.15 \mathrm{~K}$, are presented in Tables 2 and 3, respectively.

Each reported solubility value is the average of at least three different measurements. The standard deviation is also shown in Tables 2 and 3 . The maximum variation coefficients are $1.98 \%$ and $1.60 \%$, for the experiments performed at 298.15 and $313.15 \mathrm{~K}$, respectively.

In water, $\alpha$-resorcylic acid is considerable more soluble than all the other acids ranking: gentisic acid > protocatechuic acid $>$ gallic acid. In case of organic solvents, protocatechuic and gentisic acids are the most soluble; protocatechuic acid in alcohols and 2-butanone, while gentisic acid in ethyl acetate, acetonitrile and DMF. For all the systems, the solubility increases with the temperature increase, but more strongly in water than in organic solvents. For systems containing alcohols, the solubility is generally higher than in all other solvents, decreasing with the increase of the alky chain of the alcohol.

A distinct behavior was observed in the solubilities of the binary systems containing ethyl acetate, acetonitrile and 2-butanone. In the case of binary systems containing ethyl acetate and acetonitrile, the solubilities of gentisic and protocatechuic acids are much higher than the solubilities of gallic acid. For 2-butanone, the solubilities of protocatechuic and gentisic acid are considerably higher than the solubilities of gallic and $\alpha$-resorcylic acids. In addition, very high solubilities were observed for all the systems containing dimethylformamide.

\begin{tabular}{|c|c|c|c|c|}
\hline Solvent & Gallic acid & Protocatechuic acid & Gentisic acid & $\alpha$-Resorcylic acid \\
\hline Water & $1.072 \pm 0.004$ & $1.293 \pm 0.006$ & $2.196 \pm 0.004$ & $10.176 \pm 0.026$ \\
\hline Methanol & $38.623 \pm 0.196$ & $79.193 \pm 0.703$ & $67.565 \pm 0.034$ & $43.165 \pm 0.203$ \\
\hline Ethanol & $23.732 \pm 0.009$ & $55.577 \pm 0.156$ & $45.503 \pm 0.078$ & $13.068 \pm 0.006$ \\
\hline Isopropanol & $12.273 \pm 0.032$ & $45.146 \pm 0.199$ & $33.156 \pm 0.220$ & $12.823 \pm 0.047$ \\
\hline 1-Propanol & $10.585 \pm 0.088$ & $40.904 \pm 0.008$ & $35.277 \pm 0.002$ & $12.751 \pm 0.025$ \\
\hline 2-Butanone & $6.132 \pm 0.015$ & $47.174 \pm 0.026$ & $36.163 \pm 0.002$ & $3.621 \pm 0.001$ \\
\hline Ethyl acetate & $0.996 \pm 0.001$ & $7.894 \pm 0.007$ & $11.222 \pm 0.007$ & $3.317 \pm 0.004$ \\
\hline Acetonitrile & $0.492 \pm 0.004$ & $5.910 \pm 0.010$ & $7.680 \pm 0.006$ & $3.271 \pm 0.007$ \\
\hline DMF & $44.674 \pm 0.882$ & $60.557 \pm 0.246$ & $72.861 \pm 0.759$ & $47.745 \pm 0.397$ \\
\hline
\end{tabular}

Table 2

Experimental solubilities ( $\mathrm{g}$ of solute/100 g of solvent) of phenolic acids in water and organic solvents at $298.15 \mathrm{~K}$ and $0.1 \mathrm{MPa}{ }^{\mathrm{a}}$

a Temperature and pressure standard uncertainties are $u(T)=0.10 \mathrm{~K}$ and $\mathrm{u}_{\mathrm{r}}(\mathrm{p})=0.05$, respectively. 
Table 3

Experimental solubilities ( $\mathrm{g}$ of solute/100 $\mathrm{g}$ of solvent) of phenolic acids in water and organic solvents at $313.15 \mathrm{~K}$ and and $0.1 \mathrm{MPa}$.

\begin{tabular}{|c|c|c|c|c|}
\hline Solvent & Gallic acid & Protocatechuic acid & Gentisic acid & $\alpha$-Resorcylic acid \\
\hline Water & $2.417 \pm 0.039$ & $3.046 \pm 0.006$ & $5.137 \pm 0.004$ & $22.452 \pm 0.01$ \\
\hline Methanol & $41.472 \pm 0.084$ & $92.404 \pm 0.333$ & $78.613 \pm 0.366$ & $52.032 \pm 0.016$ \\
\hline Ethanol & $24.522 \pm 0.053$ & $57.987 \pm 0.136$ & $51.607 \pm 0.273$ & $16.485 \pm 0.022$ \\
\hline Isopropanol & $14.247 \pm 0.009$ & $50.261 \pm 0.062$ & $44.943 \pm 0.024$ & $16.088 \pm 0.033$ \\
\hline 1-Propanol & $11.697 \pm 0.021$ & $43.987 \pm 0.009$ & $40.499 \pm 0.013$ & $14.912 \pm 0.042$ \\
\hline 2-Butanone & $6.207 \pm 0.015$ & $48.946 \pm 0.047$ & $40.252 \pm 0.014$ & $4.395 \pm 0.008$ \\
\hline Ethyl acetate & $1.096 \pm 0.010$ & $12.991 \pm 0.019$ & $18.261 \pm 0.001$ & $5.064 \pm 0.004$ \\
\hline Acetonitrile & $0.699 \pm 0.007$ & $10.785 \pm 0.013$ & $10.989 \pm 0.014$ & $5.344 \pm 0.008$ \\
\hline $\mathrm{DMF}$ & $49.401 \pm 0.205$ & $67.244 \pm 0.398$ & $77.888 \pm 1.039$ & $53.272 \pm 0.270$ \\
\hline
\end{tabular}

a Temperature and pressure standard uncertainties are $u(T)=0.10 \mathrm{~K}$ and $\mathrm{u}_{\mathrm{r}}(\mathrm{p})=0.05$, respectively.

Whenever possible, the experimental data obtained in this work were compared to the data already published in the literature. An overview of the information available in the literature is shown in Table S2 of Supporting information. As can be seen, no solubility data were found for gentisic and $\alpha$-resorcylic acids.

As illustrated in Fig. 2, at $298.15 \mathrm{~K}$, the solubility of gallic acid in water obtained in this work $(1.072 \mathrm{~g} / 100 \mathrm{~g}$ solvent) is lower than average solubility data collected from literature $\mathrm{K}(1.339 \pm 0.232 \mathrm{~g} / 100 \mathrm{~g}$ solvent), that varies from $1.01 \mathrm{~g} / 100 \mathrm{~g}$ of solvent [16] to $1.40 \mathrm{~g} / 100 \mathrm{~g}$ of solvent [19]. At $313.15 \mathrm{~K}$, however, the solubility measured in this work ( $2.417 \mathrm{~g} / 100 \mathrm{~g}$ solvent) is closer to the literature average, being slightly higher. At both temperatures the results obtained in this work are closer to those measured by Lu and Lu (2007). The differences between different works are probably due to the level of purity of the compounds, the nature of the solid phase of the solutes, and the shaking or settling times [6,16-18]. Also deserving a note is the very small solubility increase with temperature published by Noubigh et al. [3].

A comparison between the solubility of gallic acid in different organic solvents and of protocatechuic acid in water and organic solvents are shown in Figs. 3 and 4, respectively.

The solubility of gallic acid in methanol, ethyl acetate, ethanol is always closer than $0.8 \mathrm{~g} / 100 \mathrm{~g}$ solvent to the results reported by Daneshfar et al. [17], which is quite consistent considering the solubility magnitudes. From the results published by Dali et al. [18], the values that agree the most with the results found in this work are the solubility data for the binary system gallic acid and 2-propanol. In the case of the system formed by gallic acid and 1-propanol, the solubility values published by Dali et al. [18] are higher than the values measured in this work. However, the literature data present a higher leap between the values at 293.15 and $298.15 \mathrm{~K}$, which is unusual unless a phase transition is observed. From all the studied binary systems containing gallic acid, the solubility in acetonitrile is the one presenting the highest disagreement with the values found in literature. Here, this experiment was repeated and the results obtained were the same within the uncertainty of the measurements.

In the systems containing protocatechuic acid, the data measured in this work and the literature average are very close for aqueous systems. However, considering organic solvents, the solubility data by Noubigh et al. [7] are in all cases lower than those proposed in this work. We have performed several tests and repeat the solubility measurements always finding consistent values. Those authors applied $3 \mathrm{~h}$ as stirring time to prepare the saturated solution, which might not be enough. Another explanation may be related to the solid phase system. Like discussed below, there are evidences that protocatechuic acid can present a stable hydrated form, and no information about the solid phase is reported by Noubigh et al. [7].

\subsection{Fusion properties}

Table 4 shows the melting temperature of the phenolic acids, measured in this work by DSC and a visual method, and the melting enthalpy obtained by DSC. Exemplificative thermograms are given as
Supporting information (Fig. S1). For comparison purposes, a summary of the few available literature data is also presented.

The measured melting temperatures found in this work by the two experimental methods (DSC and visual methods) are very close. In general, for protocatechuic and $\alpha$-resorcylic acids they are also in close agreement with those found in literature. Likewise, the melting temperature obtained for gentisic acid is comparable to those reported by other authors, especially to the value found by Price et al. [58]. For gallic acid, the melting point published by Bogel-Łukasik et al. [55] agrees more with the values found in this work.

Regarding the enthalpy of fusion, the literature values are much more uncertain and less consistent with each other. The results found in this work for protocatechuic and $\alpha$-resorcylic acids are very close to those measured by Vecchio [56] and Monte et al. [59], respectively. In the case of gentisic acid, only one value was found in the literature for the enthalpy of fusion, which is quite smaller than the value obtained in this work. The DSC studies on gentisic acid also point an endothermic peak before melting, between $195.6{ }^{\circ} \mathrm{C}$ and $200.8^{\circ} \mathrm{C}$.

From the mentioned dihydroxybenzoic acids, only $\alpha$-resorcylic acid presented weight loss in one of the runs performed in this work, which may indicate sample degradation. However, Monte et al. also performed studies on the phase behavior of protocatechuic acid, gentisic acid and $\alpha$-resorcylic acid, observing decomposition only for protocatechuic acid. These divergences are probably related to the solid phase nature, purity and the experimental methodology.

A major divergence is observed for gallic acid, which seems to decompose upon melting (see Fig. S1 (a)). Mota et al. [13] tried to measure the enthalpy of fusion of gallic acid via DSC and also observed some degradation during the phase change. Other authors reported values that

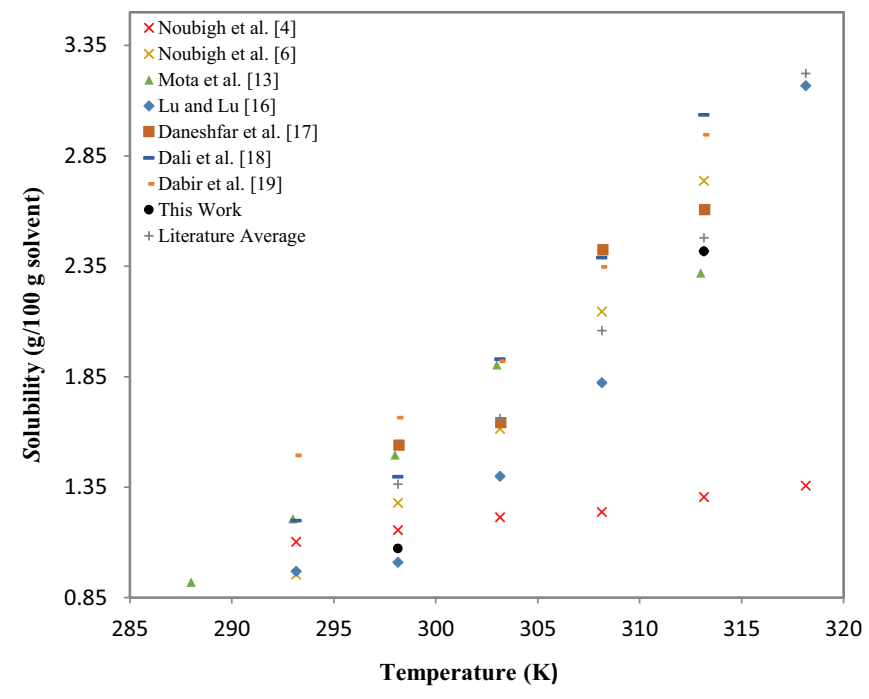

Fig. 2. Experimental solubility of gallic acid in water available in literature $[4,6,13,16-19]$ and obtained in this work. 

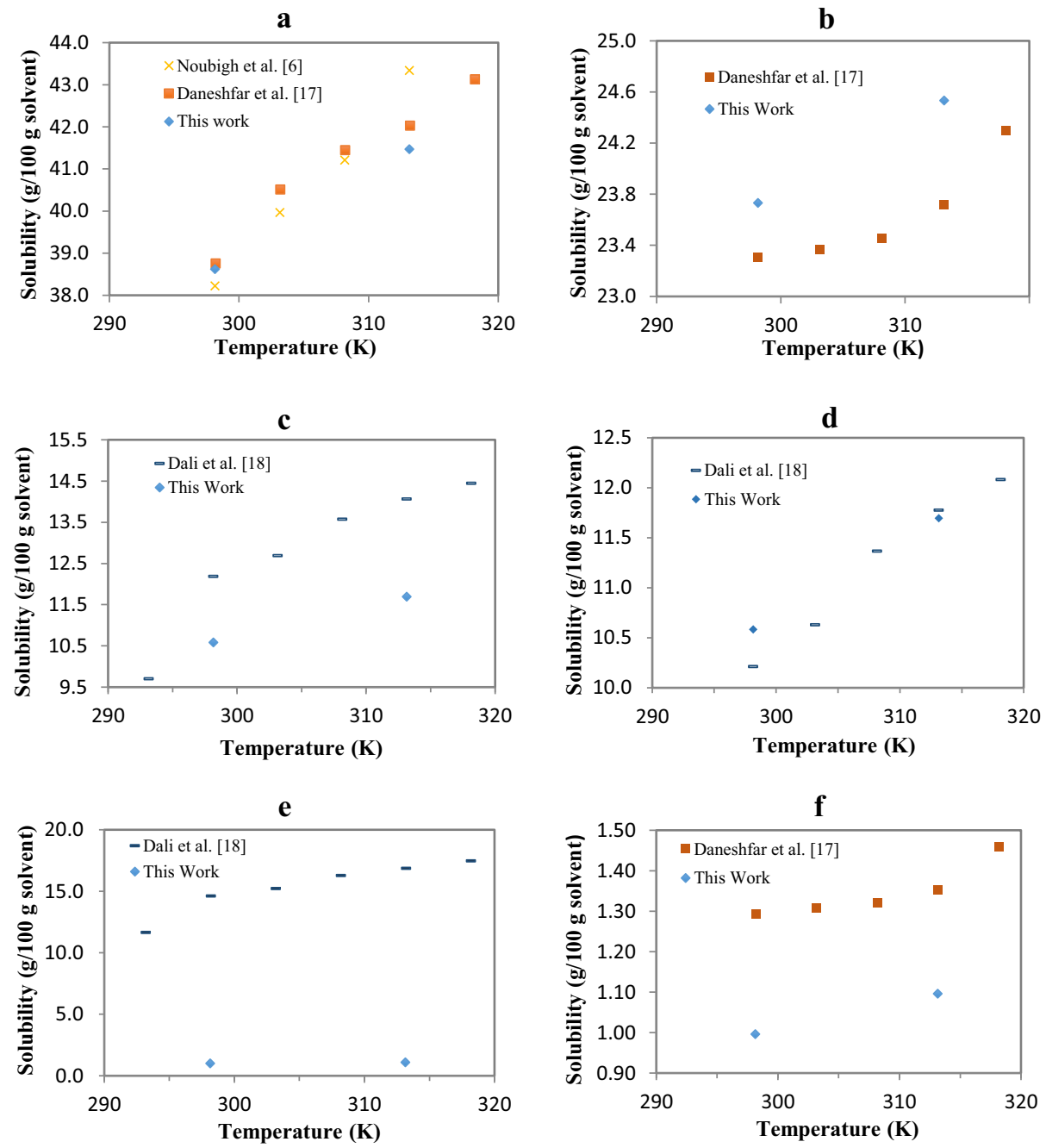

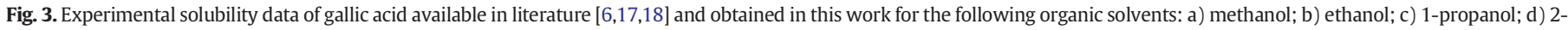
propanol; e) acetonitrile; f) ethyl acetate.

are considerably different from each other, and the one measured here presents very high standard deviation, which may indicate that DSC technique is unfeasible to measure the enthalpy of fusion of gallic acid, and probably ultra-fast DSC is a better technique to perform this measurement.

To conclude, the thermograms shown in Supporting information may be explained by some degradation phenomena, including either sublimation or other phenomena such as solid-solid transitions.

\subsection{Solid phase studies}

First, studies on the characterization of the solid phases of the selected phenolic acids were carried out as received from the suppliers. In order to facilitate the identification of the solid phases, a literature review of the previous reported structures is presented in the Supporting information (Table S3). From a single crystal, it was found that the gentisic acid crystalizes in monoclinic $P$ system with cell parameters of $\mathrm{a}=5.58 \AA, \mathrm{b}=4.90 \AA, \mathrm{c}=23.51 \AA, \beta=93.34^{\circ}$, which are comparable to those published in CCDC database (CCDC numbers: 747937747942 and 747946-747948) [61].

After a long exposure to air moisture, protocatechuic acid crystalizes in triclinic system showing the following cell parameters: $\mathrm{a}=7.927$ (3) $\AA, b=8.058(3) \AA, c=12.500(4) \AA, \alpha=77.323(13)^{\circ}, \beta=72.847$ $(13)^{\circ}$, and $\gamma=72.382(13)^{\circ}$. A search in CCDC database revealed that no sample matches these parameters, and they are different from those samples published by Sarma et al. [60]. In Fig. 5, it is presented the molecular structure of protocatechuic acid from supplier after a long contact with air moisture.

The asymmetric unit of protocatechuic acid contains two crystallographically independent protocatechuic acid units and two water solvent molecules (Fig. 5a). The crystal lattice of the protocatechuic acid from supplier is stabilized via multiple hydrogen bonding interactions among the protocatechuic acid molecules and water crystallization molecules. The dimensions of the hydrogen bonds are listed in Table 5. The protocatechuic acid units are assembled through hydroxyl group from one molecule as donor and the adjacent oxygen atom as acceptor with $0 \cdots$ O distance of $2.729(2)$ and 2.575(2) A forming dimer units, as well as with the two solvent water molecules with $0 \cdots 0$ distances ranging from 2.706 (2) to 2.854(2) $\AA$ (Fig. 5b). These bonding interactions play a decisive role in the lattice stabilization leading to the formation of a 3-D network of hydrogen bonds.

Another relevant structural feature of protocatechuic acid is the parallel disposition adopted by the protocatechuic acid rings at a centroidcentroid distance of $3.587 \AA$ and a shift distance of $1.115 \AA$, which are consistent with the existence of intermolecular $\pi \cdots \pi$ interactions.

The experimental X-ray powder diffraction pattern with the powder pattern calculated from the structure solved from single-crystal X-ray diffraction data is shown in the Supporting information (Fig. S2).

Gallic and $\alpha$-resorcylic acids showed very small particle sizes $(<20$ $\mu \mathrm{m})$, being not suitable for single crystal. Consequently, they were 
a

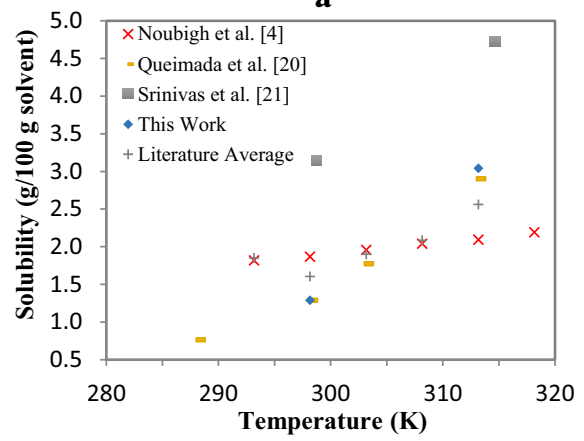

C

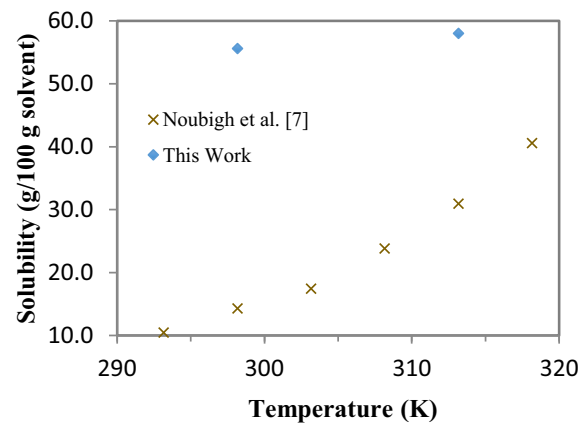

b

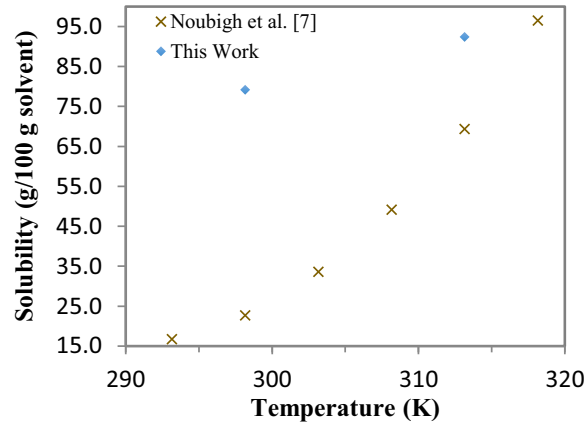

d

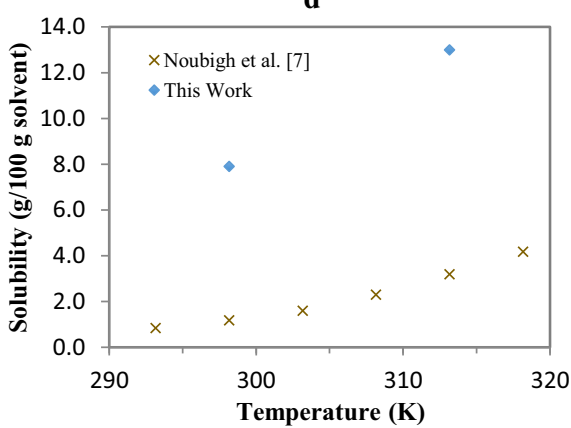

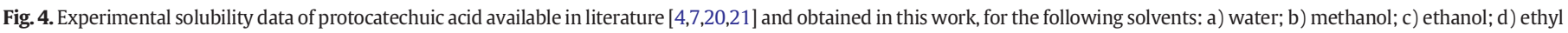
acetate.

analyzed by powder diffraction, displaying similar powder patterns when compared to those published in CCDC database (811292, 820132,837396 and 927226) for gallic acid [62-64] and 764271 for $\alpha$-resorcylic acid [60]. The complete description of the X-ray patterns

Table 4

Summary of the melting temperature and enthalpy of the studied phenolic acids. ${ }^{\mathrm{a}}$

\begin{tabular}{|c|c|c|c|c|c|}
\hline Compound & $T_{\text {fus }} / \mathrm{K}$ & $\Delta H_{\text {fus }} / \mathrm{kJ} \cdot \mathrm{mol}^{-1}$ & Methodology & Runs & Reference \\
\hline \multirow[t]{5}{*}{ Gallic acid } & 535.4 & $\mathrm{ND}^{\mathrm{b}}$ & DSC & 4 & [13] \\
\hline & $533.2 \pm 1.82$ & $65.5 \pm 3.93$ & DSC & $\mathrm{NR}^{\mathrm{c}}$ & [19] \\
\hline & $524.2 \pm 0.5$ & $62.38 \pm 0.63$ & DSC & 3 & [55] \\
\hline & $\begin{array}{l}525.2 \pm 2.94 \\
6.1\end{array}$ & $86.1 \pm 7.7$ & DSC & 4 & This work \\
\hline & $525.5 \pm 0.2$ & - & $\begin{array}{l}\text { Visual } \\
\text { method }\end{array}$ & 3 & This work \\
\hline \multirow{6}{*}{$\begin{array}{l}\text { Protocatechuic } \\
\text { acid }\end{array}$} & $472.3 \pm 1.6$ & $31.2 \pm 1.6$ & DSC & 7 & [20] \\
\hline & $474.8 \pm 0.5$ & $33.5 \pm 0.9$ & DSC & 3 & [56] \\
\hline & 474.9 & $34.0 \pm 1$ & DSC & 3 & [57] \\
\hline & 474.9 & $\mathrm{NR}^{\mathrm{c}}$ & DSC & $\mathrm{NR}^{\mathrm{c}}$ & [58] \\
\hline & $476.0 \pm 0.7$ & $33.4 \pm 0.9$ & DSC & 3 & This work \\
\hline & $474.3 \pm 0.1$ & - & $\begin{array}{l}\text { Visual } \\
\text { method }\end{array}$ & 3 & This work \\
\hline \multirow[t]{4}{*}{ Gentisic acid } & 478.9 & $\mathrm{NR}^{\mathrm{c}}$ & DSC & $\mathrm{NR}^{\mathrm{c}}$ & {$[58]$} \\
\hline & $476.2 \pm 0.2$ & $20.8 \pm 1.7^{\mathrm{d}}$ & DSC & $\mathrm{NR}^{\mathrm{c}}$ & [59] \\
\hline & $477.6 \pm 1.0$ & $29.2 \pm 1.9$ & DSC & 4 & This work \\
\hline & $476.9 \pm 0.0$ & - & $\begin{array}{l}\text { Visual } \\
\text { method }\end{array}$ & 3 & This work \\
\hline \multirow{5}{*}{$\begin{array}{l}\alpha \text {-Resorcylic } \\
\quad \text { acid }\end{array}$} & 508.9 & $\mathrm{NR}^{\mathrm{c}}$ & DSC & $\mathrm{NR}^{\mathrm{C}}$ & {$[58]$} \\
\hline & $508.3 \pm 0.2$ & $38.3 \pm 0.4$ & DSC & $\mathrm{NR}^{\mathrm{c}}$ & [59] \\
\hline & $509.9^{\mathrm{e}}$ & 29.3 & DSC & $\mathrm{NR}^{\mathrm{c}}$ & [60] \\
\hline & $510.3 \pm 0.4$ & $35.9 \pm 0.5$ & DSC & 3 & This work \\
\hline & $509.2 \pm 0.1$ & - & $\begin{array}{l}\text { Visual } \\
\text { method }\end{array}$ & 3 & This work \\
\hline
\end{tabular}

a The available standard deviations are presented after the values.

b Not determined due to decomposition upon melting.

c Not reported.

d Phase transition seems to occur immediately followed by fusion.

e Peak temperature considered as melting temperature. for gallic and $\alpha$-resorcylic acids as well as a comparison of the experimental X-ray powder diffraction pattern of protocatechuic acid from supplier with the powder pattern calculated from the single-crystal Xray diffraction data are presented in Supporting information (Figs. S2-4).

Additionally, a selected set of the solid samples obtained after the drying process (slow evaporation of the solvent, followed by a drying period in an oven at $343 \mathrm{~K}$ ), from the saturated solutions of water, methanol, 2-butanone, ethyl acetate and dimethylformamide were also analyzed by powder and single crystal X-ray diffraction. Table 6 presents an overview of the obtained results.

The crystals obtained from the evaporation of the solvent in gallic acid binary systems are comparable to those published in CCDC database (CCDC: 811292, 820132, 837396 and 927226) [62-64]. Likewise, all the crystals of $\alpha$-resorcylic acid studied in this work presented Xray patterns comparable to the one reported by Sarma et al. [60] (CCDC 764271).

Single-crystal X-ray diffraction of the protocatechuic acid obtained from the DMF solution showed crystallization in Monoclinic $P 2_{1} / c$ system with cell parameters of $\mathrm{a}=5.1683(8) \AA$, $\mathrm{b}=5.3676(8) \AA, \mathrm{c}=$ 22.533(4) $\AA$, $\beta=95.136(5)^{\circ}$, which does not match any available sample in the CCDC database. The molecular structure and the intra-hydrogen bonds formed between the protocatechuic molecules are shown in detail in Fig. S5 of the Supporting information.

The experimental powder X-ray diffraction of the protocatechuic acid samples obtained from the solutions of water, methanol, ethyl acetate and 2-butanone are similar to the powder pattern calculated from the single-crystal X-ray diffraction data of protocatechuic acid published by Sarma et al. [60] with CCDC number of 764266. This sample crystallizes in triclinic $\mathrm{P} \overline{1}$ space group with cell parameters of $\mathrm{a}=6.8800(8) \AA$, $\mathrm{b}=8.5444(10) \AA, \mathrm{c}=17.549(2) \AA, \alpha=77.982(3)^{\circ}, \beta=85.210(2)^{\circ}$ and $\gamma=85.581(2)^{\circ}[60]$.

Single crystals of the selected samples of gentisic acid obtained from gravimetry, analyzed by X-ray diffraction, show that they crystallize in monoclinic system with cell parameters of $\mathrm{a}=5.56 \AA$, b $=4.88 \AA$, c 

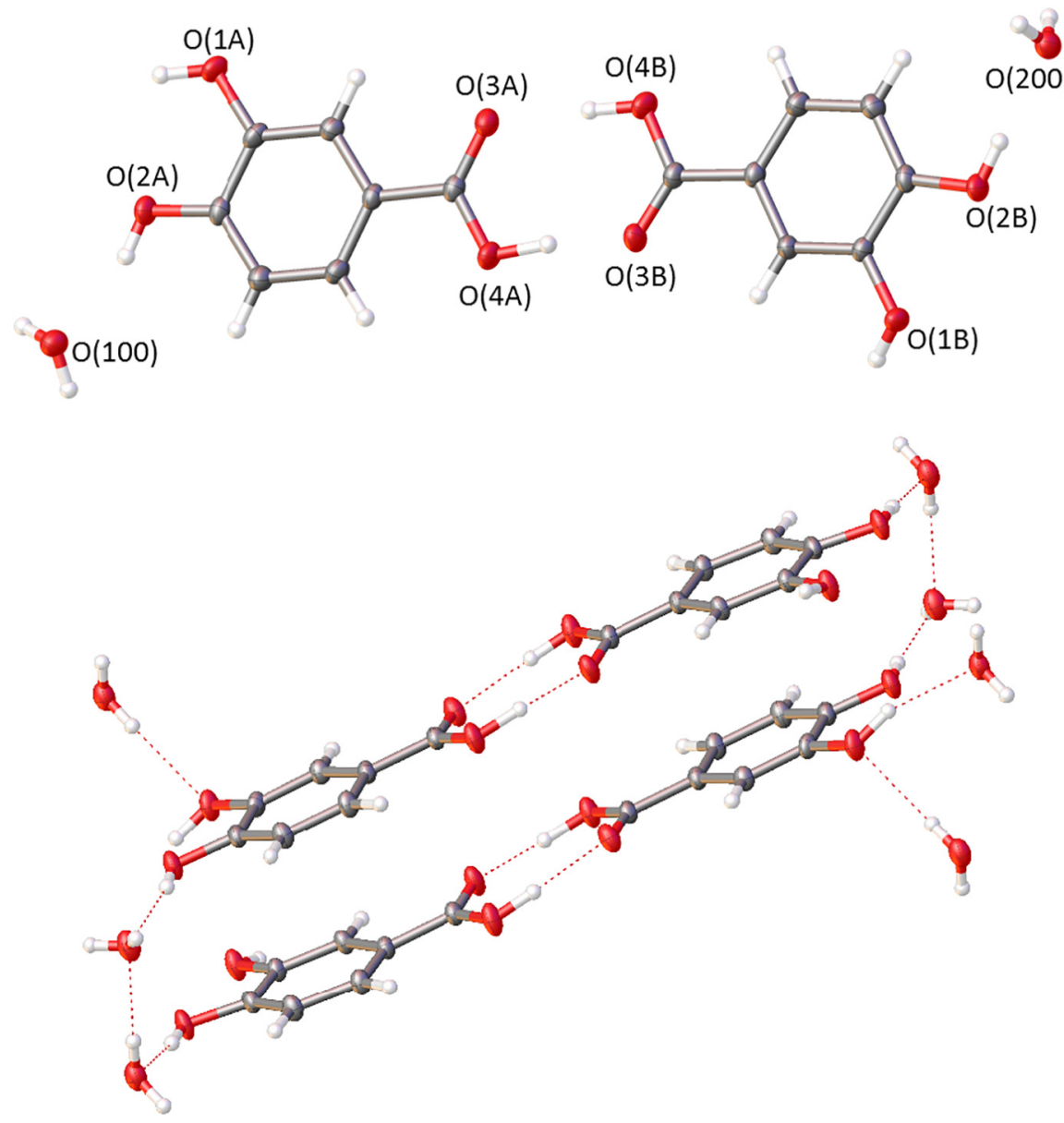

b

Fig. 5. Molecular structure of protocatechuic acid after long contact with air moisture (a). Hydrogen bonds between protocatechuic acid units as well the water solvent molecules (b).

$=23.43 \AA$, $\beta=93.35^{\circ}$ comparable to those published in CCDC database (CCDC numbers: 747937-747942 and 747946-747948) [61] and are similar to that obtained for gentisic acid from supplier.

The ID used for all the samples obtained from the evaporation of the solvent as well as the X-ray diffraction patterns for all those samples are presented in the Supporting information (Table S4 and Figs. S6-9, respectively).

\subsection{Thermodynamic modelling}

In order to optimize the NRTL-SAC segment descriptors for each of the selected phenolic acids, the model calculations were performed using the MATLAB software version R2013a. The selected optimization algorithm was the MATLAB routine Isqnonlin, which is based on nonlinear least-squares curve fitting of the objective function (relative value of the difference between the experimental and the calculated solubility data).

First, the four NRTL-SAC conceptual segments $\left(\mathrm{X}, \mathrm{Y}^{+}, \mathrm{Y}^{-}, \mathrm{Z}\right)$ were estimated for each solute by correlating part of the solubility data obtained in this work (solubility in water, methanol, ethanol, isopropanol, 2-butanone, acetonitrile and ethyl acetate). As discussed before, the melting properties have high uncertainty, and for that reason, the reference solvent approach (RSA) proposed by Abildskov and O'Connell [53] was combined to the NRTL-SAC model. To best evaluate

Table 5

Hydrogen bond dimensions for hydrated triclinic protocatechuic.

\begin{tabular}{|c|c|c|c|}
\hline $\mathrm{D}-\mathrm{H} \cdots \mathrm{A}$ & $\mathrm{H} \cdots \mathrm{A} / \AA$ & $\mathrm{D} \cdots \mathrm{A} / \AA ̊$ & $\mathrm{D}-\mathrm{H} \cdots \mathrm{A} /{ }^{\mathrm{O}}$ \\
\hline \multicolumn{4}{|l|}{ Protocatechuic acid } \\
\hline $\mathrm{O}(2 \mathrm{~A})-\mathrm{H}(2 \mathrm{~A}) \ldots \mathrm{O}(100)$ & $1.90(3)$ & $2.706(2)$ & $163(2)$ \\
\hline $\mathrm{O}(1 \mathrm{~A})-\mathrm{H}(1 \mathrm{~A}) \ldots \mathrm{O}(2 \mathrm{~A})$ & $2.30(4)$ & $2.651(2)$ & 103(3) \\
\hline $\mathrm{O}(1 \mathrm{~A})-\mathrm{H}(1 \mathrm{~A}) \ldots \mathrm{O}(200)[2+x,-1+y,-1+\mathrm{z}]$ & $2.00(4)$ & $2.854(2)$ & 156(3) \\
\hline $\mathrm{O}(1 \mathrm{~B})-\mathrm{H}(1 \mathrm{~B}) \ldots \mathrm{O}(1 \mathrm{~A})[-1+x, y, 1+\mathrm{z}]$ & $1.94(3)$ & $2.766(2)$ & $171(3)$ \\
\hline $\mathrm{O}(2 \mathrm{~B})-\mathrm{H}(2 \mathrm{~B} 1) \ldots \mathrm{O}(200)$ & $1.87(29$ & $2.717(2)$ & $174(2)$ \\
\hline $\mathrm{O}(4 \mathrm{~A})-\mathrm{H}(4 \mathrm{~A}) \ldots \mathrm{O}(3 \mathrm{~B})$ & $1.54(2)$ & $2.575(2)$ & $174(2)$ \\
\hline $\mathrm{O}(4 \mathrm{~B})-\mathrm{H}(4 \mathrm{~B}) \ldots \mathrm{O}(3 \mathrm{~A})$ & $1.79(2)$ & $2.729(2)$ & $178(2)$ \\
\hline $\mathrm{O}(100)-\mathrm{H}(10 \mathrm{~A}) \ldots \mathrm{O}(3 \mathrm{~A})[1+x,-1+y, \mathrm{z}]$ & $2.11(2)$ & $2.937(2)$ & $173(2)$ \\
\hline $\mathrm{O}(100)-\mathrm{H}(10 \mathrm{~B}) \ldots \mathrm{O}(1 \mathrm{~B})[2+x,-1+y,-1+\mathrm{z}]$ & $2.23(4)$ & $2.917(2)$ & $150(4)$ \\
\hline $\mathrm{O}(100)-\mathrm{H}(10 \mathrm{~B}) \ldots \mathrm{O}(2 \mathrm{~B})[2+x,-1+y,-1+\mathrm{z}]$ & $2.41(4)$ & $2.970(2)$ & $131(4)$ \\
\hline $\mathrm{O}(200)-\mathrm{H}(20 \mathrm{~A}) \ldots \mathrm{O}(1 \mathrm{~A})[1-x, 2-y, 1-\mathrm{z}]$ & $2.12(2)$ & $2.919(2)$ & $163(2)$ \\
\hline $\mathrm{O}(200)-\mathrm{H}(20 \mathrm{~B}) \ldots \mathrm{O}(100)[1-x, 1-y, 1-\mathrm{z}]$ & $2.04(4)$ & $2.856(2)$ & $169(4)$ \\
\hline
\end{tabular}


Table 6

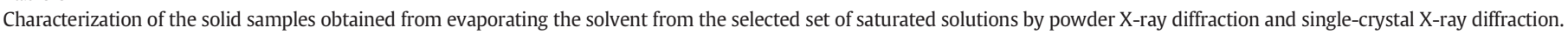

\begin{tabular}{|c|c|c|c|}
\hline Solute & Solvent (sample ID) & Solid phase (CCDC) & Experimental methodology \\
\hline \multirow[t]{5}{*}{ Gallic acid } & Water & Comparable to $811292,820132,837396$ and 927226 & Powder XRD \\
\hline & Methanol & & Powder XRD \\
\hline & 2-Butanone & & Single-crystal XRD \\
\hline & Ethyl acetate & & Powder XRD \\
\hline & $\mathrm{DMF}$ & & Powder XRD \\
\hline \multirow[t]{5}{*}{ Protocatechuic acid } & Water & 764266 & Powder XRD \\
\hline & Methanol & 764266 & Powder XRD \\
\hline & 2-Butanone & 764266 & Single-crystal XRD \\
\hline & Ethyl acetate & 764266 & Powder XRD \\
\hline & DMF & Not match found & Single-crystal XRD \\
\hline \multirow[t]{5}{*}{ Gentisic acid } & Water & Comparable to 747937-747942 and 747946-747948 & Single-crystal XRD \\
\hline & Methanol & & Single-crystal XRD \\
\hline & 2-Butanone & & Single-crystal XRD \\
\hline & Ethyl acetate & & Single-crystal XRD \\
\hline & DMF & & Single-crystal XRD \\
\hline \multirow[t]{5}{*}{$\alpha$-Resorcylic acid } & Water & Comparable to 764271 & Powder XRD \\
\hline & Methanol & & Powder XRD \\
\hline & 2-Butanone & & Powder XRD \\
\hline & Ethyl acetate & & Powder XRD \\
\hline & DMF & & Powder XRD \\
\hline
\end{tabular}

the accuracy of the results, the average relative deviations (ARD \%) were calculated for each binary system as follows:

$A R D(\%)=\frac{1}{N P} \sum_{i} \frac{\left|x_{i}^{\text {exp }}-x_{i}^{\text {calc }}\right|}{x_{i}^{\text {exp }}} * 100$

where $N P$ is the number of data points, and $x_{i}{ }^{e x p}$ and $x_{i}^{\text {calc }}$ are the experimental and calculated solubility in mole fraction, respectively.

After, the molecular descriptors were used to predict the solubility of the phenolic acids in 1-propanol and DMF. In Table 7, the optimized NRTL-SAC parameters are shown for each phenolic acid, as well as the reference solvent found, the outlier solvent presenting the highest ARD and the global ARD. The outliers were 2-butanone (protocatechuic and gentisic acids) and ethyl acetate (gallic and $\alpha$-resorcylic acids) and, in all systems, the best reference solvent was acetonitrile.

The correlation results indicate that NRTL-SAC is an adequate model to correlate the solubility of the studied compounds, with average relative deviations varying between $28 \%$ and $40 \%$. In previous works,Mota et al. $[30,33]$ have applied NRTL-SAC to predict solubility of drug molecules in water and organic solvents, such as paracetamol, furosemide, allopurinol, salicylic acid, benzoic acid and ibuprofen, reporting ARD values of $67 \%$ [33] and $41 \%$ [30], which are of the same order of magnitude to those found in this work.

In general, the solubility values in alcohols are better described if compared to those containing 2-butanone and ethyl acetate. Good correlations results were also obtained for the solubility in aqueous systems.

Once the NRTL-SAC segment parameters were obtained, the model was used to estimate the solubility in 1-propanol and DMF. The obtained ARD were $15 \%$ and $59 \%$ for 1-propanol and DMF, respectively, which indicate that NRTL-SAC is quite suitable to perform solubility predictions of the selected solvents (the results for each simulation are detailed in Fig. S10 of the Supporting information). For 1-propanol, the deviation is similar to those obtained for other alcohols during the correlation process. Besides, the experimental solubilities are in general lower in 1-propanol than in 2-propanol, behavior that is also predicted by NRTL-SAC simulations. For DMF, although the average deviation was higher than in 1-propanol, it is similar to values reported by other authors in binary systems containing small and medium size drug molecules [30,33,65-67].

Fig. 6 illustrates the big picture by presenting the calculated solubility obtained from NRTL-SAC + RSA versus the experimental solubility value. As can be seen, the model satisfactorily represents the solubility of some phenolic acids, especially for alcohols and water. The most difficult systems to describe were those containing 2-butanone and ethyl acetate, which presented ARD varying between $42 \%$ and $95 \%$, whereas systems containing alcohols and water were correlated easier, obtaining ARD varying between $8 \%$ and $33 \%$. For the predictions, the calculated solubilities of the selected solutes in DMF were lower than the experimental values, which were surprisingly high compared to the other non-alcohols solvents. Like shown in Section 4.3, for protocatechuic acid in DMF, these difficulties can also be probably connected to some solid phase change.

\section{Conclusions}

In this work, the solubility of four phenolic acids (gallic, protocatechuic, gentisic and $\alpha$-resorcylic acids) was measured in water and eight organic solvents at $298.15 \mathrm{~K}$ and $313.15 \mathrm{~K}$, using the isothermal shake-flask method, combined with gravimetric analysis. The coefficients of variation calculated from the experimental data were lower than $2 \%$, indicating the precision of the solubility measurements. By increasing the temperature, an increment in the solubility of the phenolic acids was observed. Moreover, the solubility data exhibited the same pattern for alcohols, presenting the highest solubilities for those having the shortest carbon chain. On the other hand, a distinct behavior was observed for the systems containing 2-butanone, acetonitrile and ethyl acetate. In those cases, the solubilities of protocatechuic and gentisic acids are much higher than the solubilities of gallic and $\alpha$ -

Table 7

NRTL-SAC parameters, RSA, outlier solvent and ARD (\%) for each phenolic acid.

\begin{tabular}{|c|c|c|c|c|c|c|c|}
\hline Compound & $\mathrm{X}$ & $\mathrm{Y}-$ & $\mathrm{Y}+$ & $\mathrm{Z}$ & RSA & Outlier & ARD (\%) \\
\hline Gallic acid & 0.496 & 0.418 & 0.000 & 2.300 & Acetonitrile & Ethyl acetate & 40 \\
\hline Protocatechuic acid & 0.585 & 1.112 & 0.000 & 0.734 & Acetonitrile & 2-Butanone & 28 \\
\hline Gentisic acid & 0.472 & 1.002 & 0.000 & 0.361 & Acetonitrile & 2-Butanone & 35 \\
\hline$\alpha$-Resorcylic acid & 0.187 & 0.140 & 0.000 & 1.041 & Acetonitrile & Ethyl acetate & 34 \\
\hline
\end{tabular}




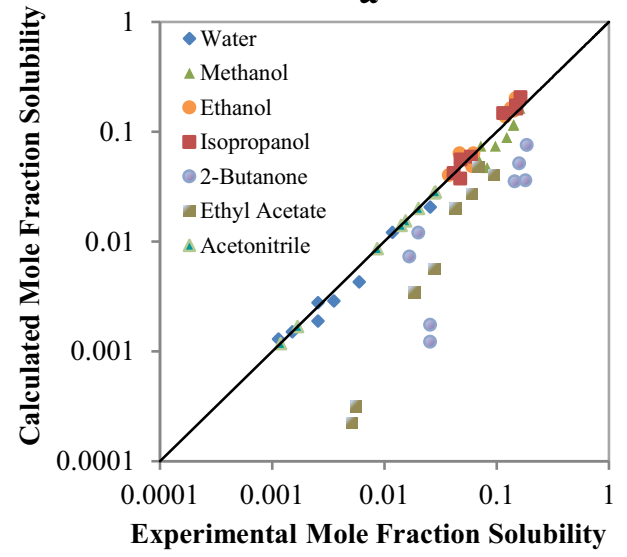

b

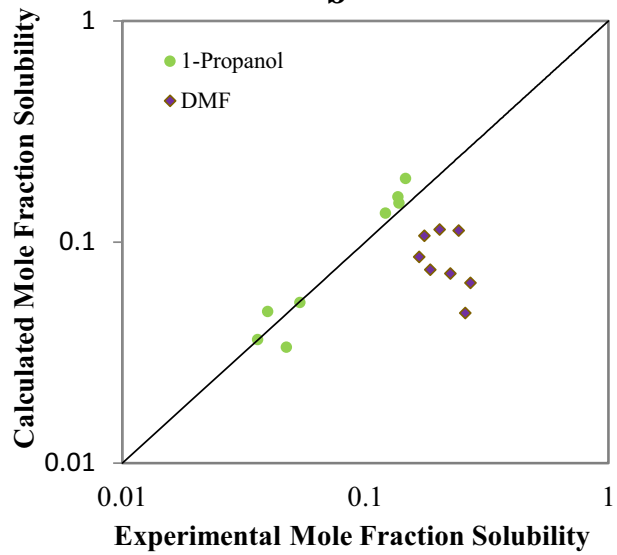

Fig. 6. Comparison between experimental and calculated solubility data for solvents used to estimate the NRTL-SAC parameters (a) and predicting set (b).

resorcylic acids. For systems containing DMF, the solubility of the four phenolic acids was surprisingly high.

Regarding the calorimetric studies, the melting temperatures of protocatechuic, gentisic and $\alpha$-resorcylic acids are in agreement with the values reported in literature. Although the uncertainties related to the enthalpies of fusion are much higher, the values estimated in this work are a relevant contribution to fill the gap on this type of phase change properties.

The solid phase studies showed that the crystals of gallic, gentisic and $\alpha$-resorcylic acids obtained from the manufacturer and from gravimetry are comparable to structures previously reported in the CSDsystem. On the other hand, crystals of protocatechuic acid from the supplier and crystals of protocatechuic acid obtained after evaporation of DMF presented structures not yet reported in the CSD-system. The other crystals from protocatechuic acid binary systems showed powder $\mathrm{X}$-ray diffraction comparable to the powder pattern calculated from the single-crystal X-ray diffraction data of protocatechuic acid published by Sarma et al. [60].

NRTL-SAC combined with the reference solvent approach was successfully employed to correlate and predict the solubility data of the selected solutes in water and in organic binary systems. The ARD varied between $28 \%$ and $40 \%$ for correlation results and between $16 \%$ and $59 \%$ for predictions. Systems containing 2-butanone or ethyl acetate are more difficult to be described, generally presenting values with a lower order of magnitude compared to the experimental solubilities.

\section{Acknowledgements}

This work is supported by: Project “AIProcMat@N2020 - Advanced Industrial Processes and Materials for a Sustainable Northern Region of Portugal 2020", supported by Norte Portugal Regional Operational Programme (NORTE 2020), under the Portugal 2020 Partnership Agreement, through the European Regional Development Fund (ERDF); Project POCI-01-0145-FEDER-006984 - Associate Laboratory LSRE-LCM funded by ERDF through COMPETE2020 - Programa Operacional Competitividade e Internacionalização (POCI); Project POCI-01-0145FEDER-030463 financed by COMPETE and Portugal2020 and national funds through FCT - Fundação para a Ciência e a Tecnologia. We also acknowledge the support of CICECO - Aveiro Institute of Materials, POCI01-0145-FEDER-007679 (Ref. FCT UID/CTM/50011/2013).

\section{Appendix A. Supplementary data}

Supplementary data to this article can be found online at https://doi. org/10.1016/j.molliq.2018.10.108.

\section{References}

[1] C.D. Stalikas, Extraction, separation, and detection methods for phenolic acids and flavonoids, J. Sep. Sci. 30 (2007) 3268-3295.

[2] A. Noubigh, A. Mgaidi, M. Abderrabba, E. Provost, W. Fürst, Effect of salts on the solubility of phenolic compounds: experimental measurements and modelling, J. Sci. Food Agric. 87 (2007) 793-788.

[3] A. Noubigh, M. Cherif, E. Provost, M. Abderrabba, Solubility of some phenolic compounds in aqueous alkali metal nitrate solutions from (293.15 to 318.15 ) K, J. Chem. Thermodyn. 40 (2008) 1612-1616.

[4] A. Noubigh, M. Cherif, E. Provost, M. Abderrabba, Solubility of gallic acid, vanillin, syringic acid, and protocatechuic acid in aqueous sulfate solutions from (293.15 to 318.15) K, J. Chem. Eng. Data 53 (2008) 1675-1678.

[5] A. Noubigh, C. Jeribi, A. Mgaidi, M. Abderrabba, Solubility of gallic acid in liquid mixtures of ( ethanol + water ) from ( 293.15 to 318.15 ) K, J. Chem. Thermodyn. 55 (2012) 75-78.

[6] A. Noubigh, A. Aydi, A. Mgaidi, M. Abderrabba, Measurement and correlation of the solubility of gallic acid in methanol plus water systems from (293.15 to 318.15 ) K, J. Mol. Liq. 187 (2013) 226-229.

[7] A. Noubigh, A. Aydi, M. Abderrabba, Experimental measurement and correlation of solubility data and thermodynamic properties of protocatechuic acid in four organic solvents, J. Chem. Eng. Data 60 (2015) 514-518.

[8] A. Noubigh, A. Akrmi, Temperature dependent solubility of vanillic acid in aqueous methanol mixtures: measurements and thermodynamic modeling, J. Mol. Liq. 220 (2016) 277-282.

[9] A. Noubigh, A. Akermi, Solubility and thermodynamic behavior of syringic acid in eight pure and water + methanol mixed solvents, J. Chem. Eng. Data 62 (2017) 3274-3283.

[10] M.A. Peña, P. Bustamante, B. Escalera, A. Reíllo, J.M. Bosque-Sendra, Solubility and phase separation of benzocaine and salicylic acid in 1,4-dioxane-water mixtures at several temperatures, J. Pharm. Biomed. Anal. 36 (2004) 571-578.

[11] F.L. Nordström, Å.C. Rasmuson, Solubility and melting properties of salicylic acid, J. Chem. Eng. Data 51 (2006) 1668-1671.

[12] J.M.P.Q. Delgado, Experimental data of solubility at different temperatures: a simple technique, Heat Mass Transf. Stoffuebertragung. 43 (2007) 1311-1316.

[13] F.L. Mota, A.J. Queimada, S.P. Pinho, E.A. Macedo, Aqueous solubility of some natural phenolic compounds Fa, Ind. Eng. Chem. Res. 47 (2008) 5182-5189.

[14] A. Shalmashi, A. Eliassi, Solubility of salicylic acid in water, ethanol, carbon tetrachloride, ethyl acetate, and xylene, J. Chem. Eng. Data 53 (2008) 199-200.

[15] R.F. Pires, M.R.F. Jr., Fluid phase equilibria solubility of salicylic acid in water + salt $\left(\mathrm{NaCl}, \mathrm{KCl}, \mathrm{NaBr}, \mathrm{Na}_{2} \mathrm{SO}_{4}\right.$ and $\left.\mathrm{K}_{2} \mathrm{SO}_{4}\right)$ at 293.5-313.3 K, Fluid Phase Equilib. 330 (2012) 48-51.

[16] L.L. Lu, X.Y. Lu, Solubilities of gallic acid and its esters in water, J. Chem. Eng. Data 52 (2007) 37-39.

[17] A. Daneshfar, H.S. Ghaziaskar, N. Homayoun, Solubility of gallic acid in methanol, ethanol, water, and ethyl acetate, J. Chem. Eng. Data 53 (2008) 776-778.

[18] I. Dali, A. Aydi, C.C. Alberto, Z.A. Wust, A. Manef, Correlation and semi-empirical modeling of solubility of gallic acid in different pure solvents and in binary solvent mixtures of propan-1-ol + water, propan-2-ol + water and acetonitrile + water from (293.2 to 318.2) K, J. Mol. Liq. 222 (2016) 503-519.

[19] T.O. Dabir, V.G. Gaikar, S. Jayaraman, S. Mukherjee, Fluid phase equilibria thermodynamic modeling studies of aqueous solubility of caffeine, gallic acid and their cocrystal in the temperature range of $303 \mathrm{~K}$ e $363 \mathrm{~K}$, Fluid Phase Equilib. 456 (2018) 65-76.

[20] A.J. Queimada, F.L. Mota, S.P. Pinho, E.A. Macedo, Solubilities of biologically active phenolic compounds: measurements and modeling, J. Phys. Chem. B 113 (2009) 3469-3476.

[21] K. Srinivas, J.W. King, L.R. Howard, J.K. Monrad, Solubility of gallic acid, catechin, and protocatechuic acid in subcritical water from (298.75 to 415.85) K, J. Chem. Eng. Data 55 (2010) 3101-3108. 
[22] Q. Li, F. Lu, Y. Tian, S. Feng, Y. Shen, B. Wang, Solubility of veratric acid in eight monosolvents and ethanol +1 -butanol at various temperatures, J. Chem. Eng. Data 58 (2013) 1020-1028

23] M.S. Manic, D. Villanueva, T. Fornari, A.J. Queimada, E.A. Macedo, V. NajdanovicVisak, Solubility of high-value compounds in ethyl lactate: measurements and modeling, J. Chem. Thermodyn. 48 (2012) 93-100.

[24] Y. Zhang, F. Guo, Q. Cui, M. Lu, X. Song, H. Tang, Q. Li, Measurement and correlation of the solubility of vanillic acid in eight pure and water + ethanol mixed solvents at temperatures from (293.15 to 323.15) K, J. Chem. Eng. Data 61 (2016) 420-429.

[25] A. Fredenslund, R.L. Jones, J.M. Prausnitz, Group-contribution estimation of activity coefficients in nonideal liquid mixtures, AIChE J 21 (1975) 1086-1099.

[26] A. Nouar, I. Benmessaoud, O. Koutchoukali, M.S. Koutchoukali, Solubility prediction of active pharmaceutical compounds with the UNIFAC model, Int. J. Thermophys. 37 (2016) 1-15.

27] D.M. Sevillano, L.A.M. Van Der Wielen, O. Trifunovic, M. Ottens, Model comparison for the prediction of the solubility of green tea catechins in ethanol/water mixtures, Ind. Eng. Chem. Res. 52 (2013) 6039-6048

28] E. Sheikholeslamzadeh, S. Rohani, Solubility prediction of pharmaceutical an chemical compounds in pure and mixed solvents using predictive models, Ind. Eng. Chem. Res. 51 (2012) 464-473.

[29] E.I. Alevizou, E.C. Voutsas, Solubilities of p-coumaric and caffeic acid in ionic liquids and organic solvents, J. Chem. Thermodyn. 62 (2013) 69-78.

[30] F.L. Mota, A.J. Queimada, A.E. Andreatta, S.P. Pinho, E.A. Macedo, Calculation of druglike molecules solubility using predictive activity coefficient models, Fluid Phase Equilib. 322-323 (2012) 48-55.

[31] H. Renon, J.M. Prausnitz, Local compositions in thermodynamic excess functions for liquid mixtures, AIChE J 14 (1968) 135-144.

[32] C.-C. Chen, Y. Song, Solubility modeling with NRTL segment activity coefficient model, Ind. Eng. Chem. Res. 43 (2004) 8354-8362.

[33] F.L. Mota, A.P. Carneiro, A.J. Queimada, S.P. Pinho, E.A. Macedo, Temperature and solvent effects in the solubility of some pharmaceutical compounds: measurements and modeling, Eur. J. Pharm. Sci. 37 (2009) 499-507.

[34] Y. Feng, W. Tang, Y. Huang, Y. Xiong, L. Chen, Y. Liu, Y. Li, (Solid + liquid) phase equilibria of tetraphenyl piperazine-1, 4-diyldiphosphonate in pure solvents, J. Chem. Thermodyn. 78 (2014) 143-151.

[35] J. Li, Z.X. Zeng, L. Sun, W.L. Xue, H.H. Wang, Solid-liquid phase equilibrium of transcinnamic acid in several alcohols: measurements and thermodynamic modeling, J. Chem. Eng. Data 61 (2016) 1192-1198.

[36] W. Ji, Q. Meng, P. Li, B. Yang, F. Wang, L. Ding, B. Wang, Measurement and correlation of the solubility of p-coumaric acid in nine pure and water + ethanol mixed solvents at temperatures from 293.15 to 333.15 K, J. Chem. Eng. Data 61 (2016) 3457-3465.

[37] D.B. Ren, Z.H. Yang, Y.Z. Liang Q. Ding C. Chen, M.L. Ouyang Correlation and prediction of partition coefficient using nonrandom two-liquid segment activity coefficient model for solvent system selection in counter-current chromatography separation, J. Chromatogr. A 1301 (2013) 10-18.

[38] D.B. Ren, L.Z. Yi, Y.H. Oin, Y.H. Yun, B.C. Deng, H.M. Lu, X.O. Chen, Y.Z. Liang, Systematic and practical solvent system selection strategy based on the nonrandom twoliquid segment activity coefficient model for real-life counter-current chromatography separation, J. Chromatogr. A 1393 (2015) 47-56.

[39] Y. Qin, Y. Liang, D. Ren, X. Qiu, X. Li, Separation of phenolic acids and flavonoids from Trollius chinensis Bunge by high speed counter-current chromatography, J Chromatogr. B Anal. Technol. Biomed. Life Sci. 1001 (2015) 82-89.

[40] M. Valavi, M. Svard, A.C. Rasmuson, Prediction of the solubility of medium-sized pharmaceutical compounds using a temperature-dependent NRTL-SAC model, Ind. Eng. Chem. Res. 55 (2016) 11150-11159.

41] D. Ren, B. Han, Z. Xin, W. Liu, S. Ma, Y. Liang, L. Yi, Computation-aided separation of seven components from Spirodela polyrrhiza (L.) via counter-current chromatography, Sep. Purif. Technol. 165 (2016) 160-165.

[42] F.L. Mota, Solubility Studies With Pharmaceutical Applications, University of Porto 2010

[43] J. Abildskov, J.P. O'Connell, Prediction of solubilities of complex medium-sized chemicals. II. Solutes in mixed solvents, Mol. Simul. 30 (2004) 367-378.
[44] O. Ferreira, S. Pinho, Solubility of flavonoids in pure solvents, Ind. Eng. Chem. Res. 51 (2012) 6586-6590

[45] J.T. Andersson, W. Schräder, A method for measuring 1-octanol-water partition coefficients, Anal. Chem. 71 (1999) 3610-3614

[46] C.R. Groom, I.J. Bruno, M.P. Lightfoot, S.C. Ward, The Cambridge structural database, Acta Crystallogr. B Struct. Sci. Cryst. Eng. Mater. 72 (2016) 171-179.

[47] L. Krause, R. Herbst-Irmer, G.M. Sheldrick, D. Stalke, Comparison of silver and molybdenum microfocus X-ray sources for single-crystal structure determination, J. Appl. Crystallogr. 48 (2015) 3-10.

[48] G.M. Sheldrick, A short history of SHELX, Acta Crystallogr. A Found. Crystallogr. 64 (2008) 112-122.

[49] O.V. Dolomanov, L.J. Bourhis, R.J. Gildea, J.A.K. Howard, H. Puschmann, OLEX2: a complete structure solution, refinement and analysis program, J. Appl. Crystallogr. 42 (2009) 339-341.

[50] C.-C. Chen, P.A. Crafts, Correlation and prediction of drug molecule solubility with the NRTL-SAC model, Comput. Aided Chem. Eng. 21 (2006) 859-864.

[51] P.B. Kokitar, E. Plocharczyk, C.-C. Chen, Modeling drug molecule solubility to identify optimal solvent systems for crystallization, Org. Process. Res. Dev. 12 (2008) 249-256.

[52] J.M. Prausnitz, R.N. Lichtenthaler, E.G. de Azevedo, Molecular Thermodynamics of Fluid-Phase Equilibria, Prentice Hall PTR, 1999.

[53] J. Abildskov, J.P. O'Connell, Predicting the solubilities of complex chemicals I. Solutes in different solvents, Ind. Eng. Chem. Res. 42 (2003) 5622-5634.

[54] J. Abildskov, J.P. O'Connell, Thermodynamic method for obtaining the solubilities of complex medium-sized chemicals in pure and mixed solvents, Fluid Phase Equilib. 228-229 (2005) 395-400.

[55] R. Bogel-Łukasik, L.M. Nobre Gonçalves, E. Bogel-Łukasik, Phase equilibrium phenomena in solutions involving tannins, flavonoids and ionic liquids, Green Chem. 12 (2010) 1947-1953.

[56] S. Vecchio, Thermogravimetric method for a rapid estimation of vapor pressure and vaporization enthalpies of disubstituted benzoic acids: an attempt to correlate vapor pressures and vaporization enthalpies with structure, Struct. Chem. 24 (2013) 1821-1827.

[57] S. Vecchio, B. Brunetti, Thermochemical study of 2,4-, 2,6- and 3,4-dihydroxybenzoic acids in the liquid phase using a TG apparatus, Thermochim. Acta 515 (2011) 84-90.

[58] D.M. Price, S. Bashir, P.R. Derrick, Sublimation properties of $x, y$-dihydroxybenzoic acid isomers as model matrix assisted laser desorption ionisation (MALDI) matrices, Thermochim. Acta 327 (1999) 167-171

[59] M.J.S. Monte, M.V. Gonçalves, M.D.M.C. Ribeiro Da Silva, Vapor pressures and enthalpies of combustion of the dihydroxybenzoic acid isomers, J. Chem. Eng. Data 55 (2010) 2246-2251.

[60] B. Sarma, P. Sanphui, A. Nangia, Polymorphism in isomeric dihydroxybenzoic acids, Cryst. Growth Des. 10 (2010) 2388-2399.

[61] M.S. Adam, M.J. Gutmann, C.K. Leech, D.S. Middlemiss, A. Parkin, L.H. Thomas, C.C. Wilson, Stability and cooperativity of hydrogen bonds in dihydroxybenzoic acids, New J. Chem. 34 (2010) 85-91.

[62] N. Hirum, S. Saithong, C. Pakawatchai, V. Tantishaiyakul, 3,4,5-Trihydroxybenzoic acid, Acta Crystallogr. E67 (2011) 787.

[63] J. Zhao, I.A. Khan, F.R. Fronczek, Gallic acid, Acta Crystallogr. E Struct. Rep. Online 67 (2011) 0316-0317.

[64] D.E. Braun, R.M. Bhardwaj, A.J. Florence, D.A. Tocher, S.L. Price, Complex polymorphic system of gallic acid - five monohydrates, three anhydrates, and over 20 solvates, Cryst. Growth Des. 13 (2013) 19-23.

[65] W. Tang, Z. Wang, Y. Feng, C. Xie, J. Wang, C. Yang, J. Gong, Experimental determination and computational prediction of androstenedione solubility in alcohol + water mixtures, Ind. Eng. Chem. Res. 53 (2014) 11538-11549.

[66] E. Sheikholeslamzadeh, C.C. Chen, S. Rohani, Optimal solvent screening for the crystallization of pharmaceutical compounds from multisolvent systems, Ind. Eng. Chem. Res. 51 (2012) 13792-13802.

[67] O. Ferreira, B. Schröder, S.P. Pinho, Solubility of hesperetin in mixed solvents, J. Chem. Eng. Data 58 (2013) 2616-2621. 